\title{
EFFECT OF MICROCRYSTALLINE CELLULOSE AS A FILLER AND/OR FILLER RETENTION AID ON THE MECHANICAL PROPERTIES OF BAGASSE PAPER SHEETS
}

\author{
AHMED EL-GENDY, MOHAMED EL-SAKHAWY, ABEER M ADEL and MONA T. AL-SHEMY \\ Cellulose and Paper Department, National Research Centre, \\ 33 El-Bohouth Str., Dokki, P.O. 12622, Giza, Egypt \\ \Corresponding author: Mohamed El-Sakhawy,elsakhawy@yahoo.com
}

Received June 6, 2020

\begin{abstract}
Microcrystalline cellulose (MCC), as a green material derived from bagasse, was investigated as an additive $(0-3 \mathrm{wt} \%)$ in the preparation of bagasse paper sheets, in comparison with cationic starch. The effect of MCC addition, in the presence of $15 \%$ kaolin or $15 \%$ calcium carbonate as paper filler, was also studied. The properties of bagasse paper sheets loaded with MCC or cationic starch, in the presence or absence of $15 \%$ kaolin or $15 \%$ calcium carbonate as paper filler, were evaluated in terms of breaking length, burst, tear, opacity and filler retention values. Also, SEM and thermal analyses of the paper sheets were performed. It was found that all the properties of the bagasse paper sheets were improved as a result of MCC or cationic starch addition and, in general, the observed improvement increased as the percent of addition increased. Calcium carbonate and cationic starch, in general, gave superior properties, compared to kaolin and MCC, respectively. Overall, MCC could be considered as an alternative economically viable paper additive.
\end{abstract}

Keywords: microcrystalline cellulose, cationic starch, paper sheets, filler, thermal properties

\section{INTRODUCTION}

Bagasse, the residue that remains after sugar extraction from sugar cane, is available in a clean condition and in huge quantities at sugar mills. Bagasse plays an increasingly vital role in the paper industry as a substitute raw material for wood fibers, not only in countries that lack forest resources, but also in countries that aim to diminish the deforestation phenomenon. Utilizing bagasse as a sustainable, renewable and cheap raw material for papermaking saves the environment from many aspects (i.e. avoids pollutants and high energy consumption). ${ }^{1}$ The research conducted on bagasse fibers has demonstrated that the chemical composition and physical properties of bagasse fibers are comparable to those of hardwood fibers. ${ }^{2}$ Pulping and bleaching of bagasse could be achieved under mild conditions, with lower chemical consumption, compared with hardwood. All kinds of paper and paperboard can be achieved using bagasse fiber.

Additives are used in huge amounts during papermaking to improve paper sheet properties.
Calcium carbonate and kaolin are the most commonly used mineral fillers in the paper industries. ${ }^{4,5}$ Fillers have an essential role in the enhancement of the opacity, brightness, dimensional stability, gloss and printability of several paper products. However, despite the benefits associated with using inorganic fillers (i.e. energy and cost savings, machine speed, increased furnish drainage rate etc.), their nonbiodegradability and non-combustibility create problems in the recycling process. Otherwise, if an organic filler, such as carbohydrate-based materials, is used instead of/or with an inorganic one, the problem can be solved or at least reduced. ${ }^{5}$ Cationic starch has been widely used as a wet end additive in papermaking due to its many advantages, such as good retention of fillers and fines, fast drainage, enhancement of mechanical strength and reduction of wastewater pollutants. A wide range of different cationic starches are known, depending on the source (wheat, potato, corn, etc.) and the degree of substitution. Therefore, different properties can be obtained, 
depending upon the type of starch used, the addition level, and the stage when it is added during the papermaking process. ${ }^{6,7}$

Microcrystalline cellulose (MCC) is nowadays known as an amazing green material for different industrial applications. ${ }^{8} \mathrm{MCC}$ is simply produced by proper acid hydrolysis of cellulose. Lignocellulosic materials as wood, bagasse, rice straw, rice husk, bean husk, etc. could be used for MCC production. MCC has been utilized as an inert formulation and filler in tablet production, and also as an antilipidemic agent. ${ }^{9-11}$ Though many studies have investigated the utilization of MCC in film making, ${ }^{12,13}$ its application in paper manufacturing is still lacking. Wilpiszewska et al. found that the addition of MCC to polysaccharide films improved not only their mechanical properties, but also their thermal and water vapor barrier behaviors. $^{8}$

Hence, the use of MCC in papermaking is a reasonable idea, since the necessary raw material and equipment are already available at pulp mills. In this study, MCC was prepared from bagasse and evaluated as a filler and/or filler retention aid for kaolin and calcium carbonate during bagasse paper sheet making. Moreover, the use of the prepared MCC in papermaking was compared with that of the already widely accepted commercial starch filler.

\section{EXPERIMENTAL}

\section{Materials}

The bagasse raw material and the unbleached pulp used in this study were kindly supplied by the Egyptian sugar cane bagasse mill Edfo Pulp Co., Upper Egypt. All the reagents used in this work were of analytical grade and used without any further purification.

\section{Chemical composition of bagasse}

The chemical composition of the bagasse raw material was determined by using different TAPPI standard methods for measuring the contents of $\alpha$ cellulose ( $\mathrm{T} 203$ os-61 for), lignin (T-222), pentosan (T-223 cm-84), and ash (T-211).

The amount of $\alpha$-cellulose was $69.43 \%$, lignin $4.26 \%$, pentosan $-26.21 \%$, and ash $-0.85 \%$. All the data are the mean of three measurements, with a significance level of $5 \%$.

\section{Filler preparation and characterizations Preparation of microcrystalline cellulose}

Microcrystalline cellulose was prepared as described earlier in detail. ${ }^{9}$ Namely, bleached bagasse pulp was hydrolyzed with $1.5 \mathrm{M}$ hydrochloric acid, under reflux for $90 \mathrm{~min}$ and at a liquor ratio of 1:20. The hydrolyzed pulps were thoroughly washed with distilled water and air-dried. The degree of polymerization (DP), as determined by the viscosity measurement of the bagasse MCC dissolved in copper-ammonium hydroxide solution, was found to be 284 .

\section{Filler modification}

The fillers were prepared as described in earlier work, with a slight modification. ${ }^{4}$ In brief, $20 \mathrm{~g}$ of filler and $130 \mathrm{~mL}$ of distilled water were added into a 500 $\mathrm{mL}$ four-neck round-bottom flask. The filler slurry was stirred to ensure sufficient mixing with $200 \mathrm{~mL}$ of freshly prepared solution containing cationic starch or microcrystalline cellulose, and the mixture was stirred for $30 \mathrm{~min}$. A freshly prepared alum solution $\left(\mathrm{Al}_{2}(\mathrm{SO} 4)_{3}\right)$ was then instantly poured into the above mixture, and the resulting mixture was further stirred for $10 \mathrm{~min}$. The modified filler slurry was then diluted to $1000 \mathrm{~mL}$ to facilitate its subsequent use. The added amount of calcium carbonate or kaolin filler to fibrous bagasse was $15 \%$ based on pulp.

Paper sheet preparation and determination of paper properties Preparation of handsheets

The pulp was beaten before paper sheet preparation up to 40 Schopper Riegler degrees ( ${ }^{\circ} \mathrm{SR} 40$ ) according to TAPPI Standard TAPPI T200 sp-06. Conventional handsheets, of basis weight of $60 \mathrm{~g} \cdot \mathrm{m}^{-2}$, were prepared on a Rapid Khöten sheet former, following the standard method IS0 5269-2. The beaten pulp was used at a concentration of $2 \mathrm{~g} \cdot \mathrm{L}^{-1}$. The added amount of kaolin filler was $15 \%$ based on pulp.

One liter of this fiber dispersion was introduced into the cylinder of the handsheet former. This volume was then diluted in 5-7 L of water. After a stirring phase (air injection avoids aeration), the dispersion was filtrated on a wire mesh. After pressing, the wet sheet was collected on blotting paper, protected between two sheets, and dried under vacuum at $80{ }^{\circ} \mathrm{C}$ for $10 \mathrm{~min}$. The pulp handsheets were conditioned for at least $48 \mathrm{~h}$ before starting the tests at $23 \pm 1{ }^{\circ} \mathrm{C}$ and $50 \pm 2 \%$ relative humidity, following the standard ISO 187-1977. Testing of the pulp handsheets was performed in the same conditioning chamber where the handsheets were conditioned. For each parameter, a minimum of ten readings was taken from each lot of samples and the average value was reported.

\section{Tensile strength}

The tensile strength was done on a test strip of 15 $\mathrm{mm}$ in diameter (cut from the test handsheets), using a Lorentzen \& Wettre (L\&W) tensile tester, according to the standard method ISO 1924/2-1994. The distance between the two clamps was kept at $10 \mathrm{~cm}$ and the elongation rate was normalized at $10 \mathrm{~mm} \cdot \mathrm{min}^{-1}$. The following parameters were calculated automatically by the equipment at the end of the test provided that the basis weight and thickness of the test sheet were pre- 
fed: force $(\mathrm{N})$, tensile index $\left(\mathrm{Nm} \cdot \mathrm{g}^{-1}\right)$, breaking length $(\mathrm{km})$, stretch $(\%)$, tensile energy absorption (TEA) $\left(\mathrm{J} \cdot \mathrm{m}^{-2}\right)$, TEA index $\left(\mathrm{J} \cdot \mathrm{g}^{-1}\right)$, tensile stiffness $\left(\mathrm{kN} \cdot \mathrm{m}^{-1}\right)$, elastic modulus (GPa), and tensile stiffness index (TSI) $\left(\mathrm{kN} \cdot \mathrm{m} \cdot \mathrm{g}^{-1}\right)$. These measurements were performed 10 times and the experimental error was within 5\%.

\section{Tear strength}

The test was carried out on a test piece of $65 \times 50$ $\mathrm{mm}$, cut from the test sheet, using an Adamel Lhomargy tearing strength tester, according to ISO 1974-1990. Tearing index $\left(\mathrm{I}_{\mathrm{D}}\right)$ was expressed in $\mathrm{mN} \cdot \mathrm{m}^{2} \cdot \mathrm{g}^{-1}$ and calculated as follows (Eq. 1):

$\mathrm{I}_{\mathrm{D}}=100 \times(\mathrm{D} / \mathrm{W})$

where $\mathrm{D}$ is the tearing resistance $(\mathrm{mN})$ and $\mathrm{W}$ is the basis weight $\left(\mathrm{g} \cdot \mathrm{m}^{-2}\right)$. These measurements were also carried out at least in triplicate and the experimental error was within $5 \%$

\section{Burst strength}

Burst strength was carried out on both sides of the test piece using an Adamel Lhomargy burst tester, according to ISO 2758-1983. The burst index $\left(\mathrm{I}_{\mathrm{E}}\right)$, expressed in $\mathrm{kPa} \cdot \mathrm{m}^{2} \cdot \mathrm{g}^{-1}$, was calculated as follows (Eq. 2):

$\mathrm{I}_{\mathrm{E}}=(\mathrm{P} / \mathrm{W})$

where $\mathrm{P}$ is the pressure at the time of burst $(\mathrm{kPa})$ and $\mathrm{W}$ is the basis weight $\left(\mathrm{g} \cdot \mathrm{m}^{-2}\right)$. These measurements were also carried out at least in triplicate and the experimental error was within $5 \%$.

\section{Opacity}

The opacity of the prepared handsheets was investigated by using an Elrephodatacolor 2000 instrument. Before the measurement, the instrument was calibrated according to the TAPPI standard (T 452 om-08, TAPPI standard methods: e 2008). The measurement was done on a sample thick enough to be opaque, often represented by several layers of a simply folded sheet of the sample. The opacity coefficient of the pulp handsheets was measured at monochromatic light of $\lambda=557 \mathrm{~nm}$. These measurements were carried out at least in duplicate.

\section{Determination of filler retention}

The retention of fillers was evaluated according to the following relation (Eq. 3):

Filler retention value; $\%=100 \times\{$ Retained filler (g)/Added amount of filler $(\mathrm{g})\}$

The test was repeated at least in duplicate and the difference between the various values obtained was within an experimental error of $5 \%$.

\section{Scanning electron microscopy}

The surface characteristics of MCC and bagasse handsheets were observed using scanning electron microscopy (TESCAN VEGA3 SEM, with an acceleration voltage of $10 \mathrm{kV}$ ). Each sample was coated with gold/palladium before the analysis.

\section{Thermal gravimetric analysis}

Thermal analysis was carried out using a PerkinElmer thermogravimetric analyzer. The heating rate was set to $10{ }^{\circ} \mathrm{C} / \mathrm{min}$ over a temperature range between 50 and $600{ }^{\circ} \mathrm{C}$. Measurements were carried out in a nitrogen atmosphere; the nitrogen flow rate was $50 \mathrm{~cm}^{3} / \mathrm{min}$.

\section{RESULTS AND DISCUSSION Effect of microcrystalline cellulose (MCC) as paper additive}

Microcrystalline cellulose (MCC) was prepared from bagasse $\alpha$-cellulose with a yield of $82.65 \%$ and used as an additive to bagasse paper sheets. Figure 1 displays the SEM of the prepared MCC. Mixed cellulose microfiber strands and patchy fiber crumbs can be observed as a result of the acid hydrolysis process of bleached bagasse pulp.

The data in Table 1 depict the effect of MCC addition on the mechanical properties of bagasse paper sheets, in comparison with commercial cationic starch (CCS). Different additions of MCC or CCS (from 0 to $3 \%$ based on pulp weight) were investigated.

The breaking length of the paper sheets, as shown in Table 1, increased in direct proportion with the added amount of both additives. By increasing the added amounts of MCC and CCS from 0 to $3 \%$, the breaking length increased by 12.5 and $26 \%$, respectively. The most pronounced improvement in breaking length by increasing the amount of additive \% $((\mathrm{X} 1-\mathrm{X}) / \mathrm{X})$ was noticed at 2 and $2.5 \%$ for MCC, and 1, 2 and $2.5 \%$ for CCS. It is apparent that CCS leads to superior improvement in $\mathrm{BL}$ to $\mathrm{MCC}$, but it is worth noticing that the $\mathrm{BL}$ values using 1.5, 2, 2.5 and $3 \% \mathrm{MCC}$ are comparable to the values obtained using $0.5,1,1.5$ and $2 \% \mathrm{CCS}$. This means that the improvement attained by $\mathrm{CCS}$ could be attained using the same amount of $\mathrm{MCC}+1 \%$, which is considered economically viable.

Table 1 shows that the burst index gradually increased by increasing $\mathrm{MCC}$ addition to a maximum improvement of $14.4 \%$ at $2 \% \mathrm{MCC}$ addition. CCS shows the same behavior with a maximum improvement of $28.5 \%$ at $1.5 \% \mathrm{CCS}$ addition. The tear index of the paper sheets improved by increasing the additives $\%$ to an optimum addition at $2.5 \%$, where it increased by 40.4 and $26.7 \%$ for MCC and CCS, respectively. 


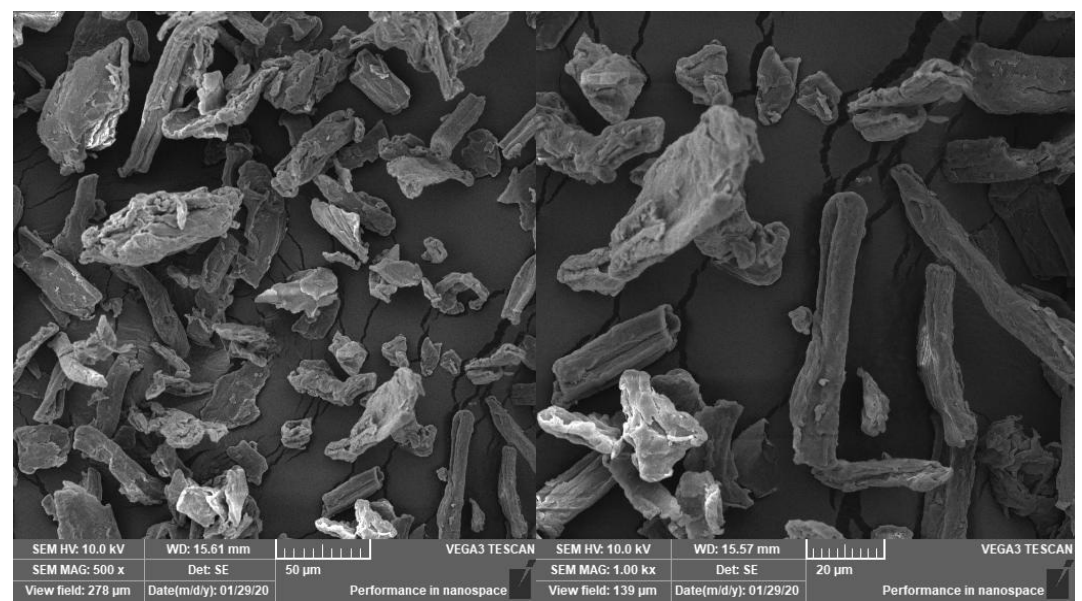

Figure 1: SEM micrograph of bagasse MCC

Table 1

Mechanical properties of bagasse paper sheets containing different amounts of microcrystalline cellulose (MCC) or commercial cationic starch (CCS)

\begin{tabular}{cccc}
\hline \multirow{2}{*}{$\begin{array}{c}\text { Added amount } \\
(\%)\end{array}$} & \multicolumn{3}{c}{ Microcrystalline cellulose (MCC) } \\
\cline { 2 - 4 } 0.00 & Breaking length $(\mathrm{km})$ & Burst index $\left(\mathrm{KPa} \cdot \mathrm{m}^{2} \cdot \mathrm{g}^{-1}\right)$ & Tear index $\left(\mathrm{mN} \cdot \mathrm{m}^{2} \cdot \mathrm{g}^{-1}\right)$ \\
0.50 & 5.06 & 3.83 & 10.33 \\
1.00 & 5.16 & 4.20 & 12.44 \\
1.50 & 5.20 & 4.33 & 12.71 \\
2.00 & 5.28 & 4.17 & 12.85 \\
2.50 & 5.47 & 4.38 & 12.56 \\
3.00 & 5.61 & 4.21 & 14.50 \\
Added amount & 5.69 & 4.21 & 14.54 \\
$(\%)$ & \multicolumn{3}{c}{} \\
\hline 0.00 & Breaking length $(\mathrm{km})$ & Burst index $\left(\mathrm{KPa} \cdot \mathrm{m}^{2} \cdot \mathrm{g}^{-1}\right)$ & Tear index $\left(\mathrm{mN} \cdot \mathrm{m}^{2} \cdot \mathrm{g}^{-1}\right)$ \\
0.50 & 5.06 & 3.83 & 10.33 \\
1.00 & 5.20 & 4.00 & 10.55 \\
1.50 & 5.55 & 4.74 & 11.00 \\
2.00 & 5.65 & 4.92 & 11.64 \\
2.50 & 5.89 & 4.43 & 12.04 \\
3.00 & 6.24 & 4.55 & 13.09 \\
& 6.38 & 4.34 & 13.00 \\
\hline
\end{tabular}

Effect of microcrystalline cellulose (MCC) as paper additive in the presence of filler

The effect of MCC addition on the mechanical properties of the bagasse paper sheets, when using $15 \%$ kaolin or $15 \%$ calcium carbonate as filler, in comparison with the addition of commercial cationic starch, was studied. Table 2 shows that the addition of fillers decreased the BL by 9.1 and $3.6 \%$ for kaolin and calcium carbonate, respectively. The addition of MCC, in the presence of the filler, compensates for the deteriorating effect of filler addition and $\mathrm{BL}$ increased as the addition \% of MCC increased to a 10.7 and $7.7 \%$ increment at 3\% MCC addition in the presence of kaolin and calcium carbonate, respectively. The improvement in $\mathrm{BL}$ upon $\mathrm{MCC}$ addition was more pronounced in the presence of kaolin than in the case of calcium carbonate. Table 2 shows that the burst index was slightly improved upon MCC addition, while the tear index increased by 29.9 and $40.7 \%$ in the presence of kaolin and calcium carbonate, respectively. Filler addition in case of both kaolin and calcium carbonate slightly increased the opacity of the paper sheets, but a more pronounced improvement in sheet opacity was attained as a result of MCC addition.

CCS addition in the presence of the fillers (Table 3) leads to the same trend as in the case of MCC addition, but with a higher improvement in 
BL (22.5 and 24.5\%) and lower improvement in tear index (17.8 and 16.2\%) in the presence of kaolin and calcium carbonate, respectively.

Opacity is an important property for printing paper. Both kaolin and calcium carbonate gave comparable opacity values for paper sheets. Paper sheet opacity increased by $2.8-4$ and $6.3-7.3 \%$ in the presence of MCC and CCS, respectively.

Table 2

Mechanical properties of bagasse paper sheets containing 15\% kaolin or $15 \%$ calcium carbonate in the presence of different amounts of microcrystalline cellulose (MCC)

\begin{tabular}{lcccc}
\hline $\begin{array}{l}\text { Added amount of filler } \\
\text { and MCC\% }\end{array}$ & $\begin{array}{c}\text { Breaking length } \\
(\mathrm{km})\end{array}$ & $\begin{array}{c}\text { Burst index } \\
\left(\mathrm{KPa} \cdot \mathrm{m}^{2} \cdot \mathrm{g}^{-1}\right)\end{array}$ & $\begin{array}{c}\text { Tear index } \\
\left(\mathrm{mN} \cdot \mathrm{m}^{2} \cdot \mathrm{g}^{-1}\right)\end{array}$ & $\begin{array}{c}\text { ISO Opacity } \\
(\%)\end{array}$ \\
\hline Blank $(\mathrm{B})$ & 5.06 & 3.83 & 10.33 & 86.62 \\
$\mathrm{~B}+$ Kaolin & 4.60 & 3.68 & 12.56 & 86.85 \\
$1 \% \mathrm{MCC} /$ Kaolin & 4.99 & 3.98 & 12.94 & 90.48 \\
$2 \% \mathrm{MCC} /$ Kaolin & 5.29 & 3.82 & 13.02 & 90.10 \\
$3 \% \mathrm{MCC} /$ Kaolin & 5.60 & 3.91 & 13.42 & 90.65 \\
$\mathrm{~B}+\mathrm{CaCO}$ & 4.88 & 4.04 & 13.20 & 88.54 \\
$1 \% \mathrm{MCC} / \mathrm{CaCO}_{3}$ & 4.86 & 3.87 & 13.84 & 89.39 \\
$2 \% \mathrm{MCC} / \mathrm{CaCO}_{3}$ & 5.17 & 3.99 & 13.79 & 89.96 \\
$3 \% \mathrm{MCC} / \mathrm{CaCO}_{3}$ & 5.45 & 3.92 & 14.54 & 90.00 \\
\hline
\end{tabular}

Table 3

Mechanical properties of bagasse paper sheets containing 15\% kaolin or $15 \%$ calcium carbonate in the presence of different amounts of cationic starch (CCS)

\begin{tabular}{lcccc}
\hline $\begin{array}{l}\text { Added amount of filler } \\
\text { and CCS\% }\end{array}$ & $\begin{array}{c}\text { Breaking length } \\
(\mathrm{km})\end{array}$ & $\begin{array}{c}\text { Burst index } \\
\left(\mathrm{KPa} \cdot \mathrm{m}^{2} \cdot \mathrm{g}^{-1}\right)\end{array}$ & $\begin{array}{c}\text { Tear index } \\
\left(\mathrm{mN} \cdot \mathrm{m}^{2} \cdot \mathrm{g}^{-1}\right)\end{array}$ & $\begin{array}{c}\text { ISO Opacity } \\
(\%)\end{array}$ \\
\hline Blank $(\mathrm{B})$ & 5.06 & 3.83 & 10.33 & 86.62 \\
$\mathrm{~B}+$ Kaolin & 4.60 & 3.68 & 12.56 & 86.85 \\
$1 \% \mathrm{CCS} /$ Kaolin & 5.46 & 3.86 & 13.32 & 93.06 \\
$2 \% \mathrm{CCS} /$ Kaolin & 5.75 & 4.06 & 12.06 & 93.91 \\
$3 \% \mathrm{CCS} / \mathrm{Kaolin}$ & 6.20 & 3.55 & 12.17 & 92.96 \\
$\mathrm{~B}+\mathrm{CaCO}$ & 4.88 & 4.04 & 13.20 & 88.54 \\
$1 \% \mathrm{CCS} / \mathrm{CaCO}_{3}$ & 5.78 & 3.77 & 11.92 & 93.57 \\
$2 \% \mathrm{CCS} / \mathrm{CaCO}_{3}$ & 6.00 & 3.79 & 11.98 & 93.73 \\
$3 \% \mathrm{CCS} / \mathrm{CaCO}_{3}$ & 6.30 & 3.84 & 12.00 & 93.82 \\
\hline
\end{tabular}

Table 4

Retention values of kaolin and calcium carbonate in paper sheets containing different amounts of microcrystalline cellulose (MCC) or cationic starch (CCS)

\begin{tabular}{lcccc}
\hline \multirow{2}{*}{$\begin{array}{l}\text { Added } \% \\
\text { of } \mathrm{MCC} \text { or CCS }\end{array}$} & $\begin{array}{c}\text { Retention value }(\%) \\
\text { +MCC }\end{array}$ & $\begin{array}{c}15 \% \mathrm{~K} \\
+\mathrm{CCS}\end{array}$ & $\begin{array}{c}15 \% \mathrm{CaCO}_{3} \\
+\mathrm{MCC}\end{array}$ & $\begin{array}{c}15 \% \mathrm{CaCO}_{3} \\
+\mathrm{CCS}\end{array}$ \\
\hline 0.00 & 31.26 & 31.26 & 35.19 & 35.19 \\
1.00 & 33.67 & 35.06 & 37.40 & 39.55 \\
2.00 & 36.09 & 39.19 & 39.07 & 41.82 \\
3.00 & 38.02 & 41.12 & 41.15 & 43.05 \\
\hline
\end{tabular}

Effect of microcrystalline cellulose (MCC) as retention aid for fillers

Table 4 shows that the addition of MCC increased the filler retention gradually for both kaolin and calcium carbonate. The retention value of kaolin increased by $21.6 \%$, while the retention value of calcium carbonate increased by $16.9 \%$ when 3\% MCC was added. CCS addition gave superior retention values, compared with MCC. At 3\% CCS addition, the retention values of 
kaolin and calcium carbonate increased by 31.5 and $22.3 \%$, respectively. For all the tested samples, calcium carbonate shows higher retention values than kaolin.

\section{Scanning electron microscopy}

The morphology and surface characteristics of the bagasse paper sheets, with different fillers and different additives, were observed by scanning electron microscopy, as shown in Figure 2.
Surface roughness and tiny pores could be detected on the blank bagasse sheets. Homogeneous fiber coating could be observed for the bagasse sheets coated by CCS or MCC. Tiny calcium carbonate particles could be noticed when calcium carbonate was used as filler in the paper sheets. CCS and MCC helped the calcium carbonate particles to adhere to cellulosic fibers, so the retention was increased. The same trend was recognized when kaolin was used as filler, with/without CCS or MCC.
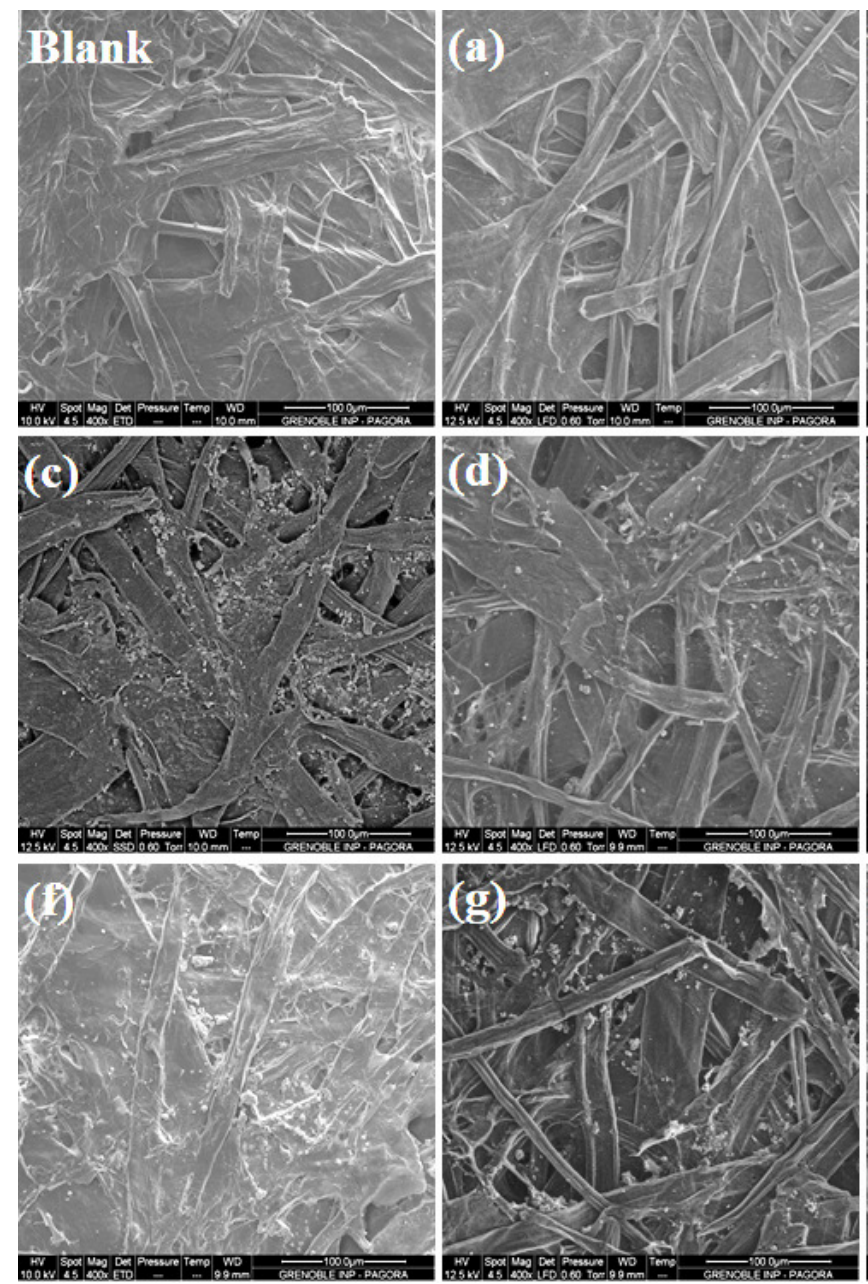
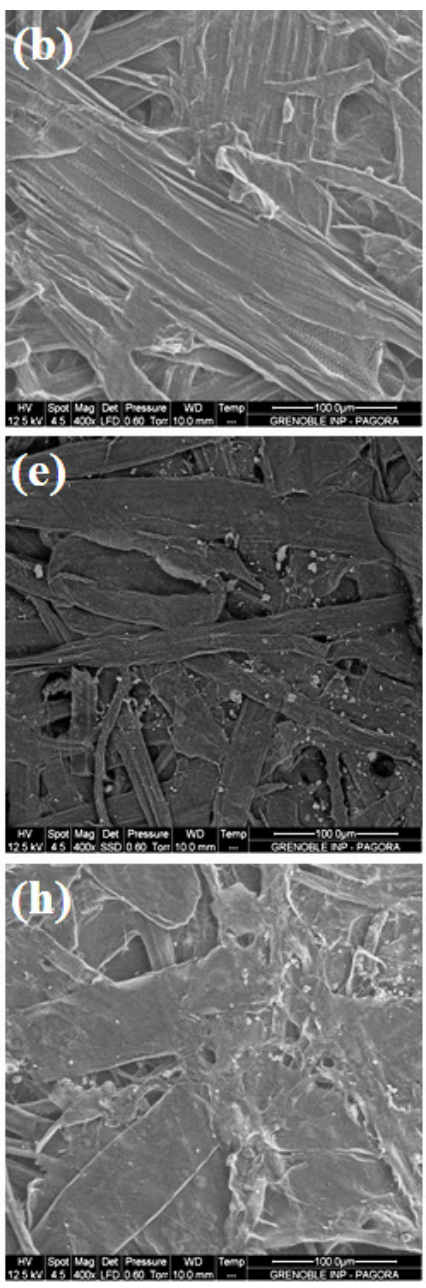

Figure 2: SEM of unfilled blank paper and paper sheets containing (a) $\mathrm{CCS}$; (b) $\mathrm{MCC}$; (c) $\mathrm{CaCO}_{3}$; (d) $\mathrm{MCC} / \mathrm{CaCO}_{3}$; (e) $\mathrm{CCS} / \mathrm{CaCO}_{3}$; (f) kaolin; (g) CCS/kaolin; (h) $\mathrm{MCC} / \mathrm{kaolin}$

\section{Thermal gravimetric analysis}

The possible influence of the MCC filler on the thermal stability of the prepared bagasse paper samples was evaluated by thermal gravimetric and differential thermal analyses, taking paper sheets treated with $15 \%$ kaolin as an example. The blank bagasse paper sheet shows the two peaks characteristic of cellulosic materials decomposition. ${ }^{14}$ The first stage, with about $10 \%$ weight loss, at about $90{ }^{\circ} \mathrm{C}$ and below $130{ }^{\circ} \mathrm{C}$, is assigned to the loss of moisture content (dehydration process). Meanwhile, the second stage (combustion process) that occurred at 357 ${ }^{\circ} \mathrm{C}$, with about $70 \%$ weight loss, is due to the decomposition of cellulosic fibers. ${ }^{15}$ The left shoulder to the second decomposition step could 
be attributed to hemicellulose degradation hemicelluloses decompose first and overlap with cellulose decomposition. About $80 \%$ of the sample weight was decomposed at $\approx 500{ }^{\circ} \mathrm{C}$. The paper sheets loaded with $15 \%$ kaolin only and those with $15 \%$ kaolin/1-3\% MCC show the same thermal behavior. The addition of kaolin to bagasse paper shifts the onset of degradation and the main decomposition temperatures towards lower values around $313.71{ }^{\circ} \mathrm{C}$ and $350.5{ }^{\circ} \mathrm{C}$, respectively. The addition of MCC compensated this difference, as can be seen in Figure 3 and Table 5. The residual char at $600{ }^{\circ} \mathrm{C}\left(\mathrm{R}_{600}\right)$ is also affected by the treatment and revealed moderate thermal stabilization of the paper sheets.

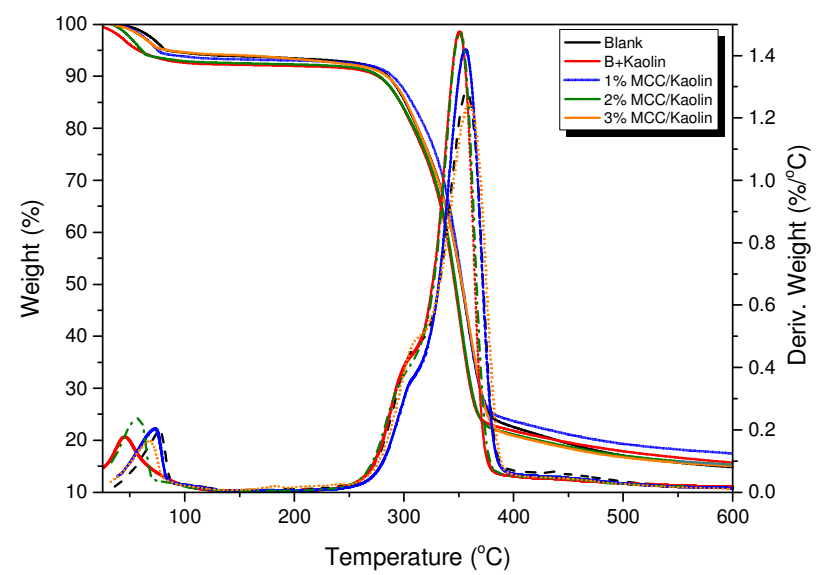

Figure 3: TGA and DTG curves of bagasse paper sheets treated with $15 \%$ kaolin and $1 \%, 2 \%$ and $3 \%$ MCC

Table 5

Thermal analysis data from TGA and DTG analyses

\begin{tabular}{lccc}
\hline Sample & $\mathrm{T}_{\mathrm{o}}$ & $\mathrm{T}_{\mathrm{m}}$ & $\mathrm{R}_{600}$ \\
\hline Blank & 314.69 & 357.08 & 14.80 \\
B+Kaolin & 313.71 & 350.50 & 15.68 \\
1\%MCC/Kaolin & 317.34 & 355.77 & 17.32 \\
2\%MCC/Kaolin & 315.35 & 351.09 & 15.34 \\
3\%MCC/Kaolin & 311.37 & 359.07 & 15.04 \\
\hline
\end{tabular}

\section{CONCLUSION}

Microcrystalline cellulose (MCC) was prepared from bagasse $\alpha$-cellulose with a yield of $82.65 \%$ and used as an additive in the manufacture of bagasse paper sheets, in comparison with commercial cationic starch. The mechanical properties of the paper sheets increased in direct proportion with the added amount of both additives, but CCS caused superior improvement in BL to MCC. It is worth noticing that the improvement attained by CCS could be attained using MCC with a $1 \%$ higher added value, which can be considered economically viable. The properties of bagasse paper sheets were improved as a result of MCC or cationic starch addition in the presence of $15 \%$ kaolin or $15 \%$ calcium carbonate as paper filler and also the filler retention increased.
ACKNOWLEDGMENT: The authors would like to express their gratitude to the National Research Centre, Egypt, for the financial support of the current work.

\section{REFERENCES}

1 A. H. Hemmasi, A. Samariha, A. Tabei, M. Nemati and A. Khakifirooz, Am. J. Agric. Environ. Sci., 11, 478

(2011),

https://www.idosi.org/aejaes/jaes11(4)11/4.pdf

2 E. Abd El-Sayed, M. El-Sakhawy and M. A. ElSakhawy, Nord. Pulp Pap. Res. J., 35, 215 (2020), https://doi.org/10.1515/npprj-2019-0064

T. J. Rainey and G. Covey, in "Sugarcane-based Biofuels and Bioproducts", edited by I. M. O'Hara and S. G. Mundree, John Wiley and Sons, 2016, pp. 259280, https://doi.org/10.1002/9781118719862.ch10

4 A. El-Gendy, R. Khiari, F. Bettaieb, N. Marlin and A. Dufresne, Appl. Clay Sci., 101, 626 (2014), https://doi.org/10.1016/j.clay.2014.09.032 
5 J. Shen, Z. Song, X. Qian and Y. Ni, Carbohyd. Polym., 85 , 17 (2011), https://doi.org/10.1016/j.carbpol.2011.02.026

6 W. Nachtergaele, Starch, 41, 27 (1989), https://doi.org/10.1002/star.19890410108

T. Hongbo, L. Yanping, M. Haoran and S. Min, Cellulose Chem. Technol., 54, 265 (2020), https://doi.org/10.35812/CelluloseChemTechnol.2020. 54.28

8 K. Wilpiszewska and Z. Czech, Starch, 66, 660 (2014), https://doi.org/10.1002/star.201300093

9 A. M. Adel, Z. H. Abd El-Wahab, A. A. Ibrahim and M. T. Al-Shemy, Carbohyd. Polym., 83, 676 (2011), https://doi.org/10.1016/j.carbpol.2010.08.039

10 M. El-Sakhawy and M. L. Hassan, Carbohyd. 67, 1 (2007), https://doi.org/10.1016/j.carbpol.2006.04.009

11 A. M. Adel and N. A. El-Shinnawy, Int. J. Biol. Macromol.

51 , 1091 https://doi.org/10.1016/j.ijbiomac.2012.08.003
12 D. Hermawan, T. K. Lai, S. J. Jafarzadeh, D. A. Gopakumar, M. Hasan et al., Bioresources, 14, 3389 (2019), https://bioresources.cnr.ncsu.edu/wpcontent/uploads/2019/03/BioRes_14_2_3389_Hermaw an_LJGMTARK_Devel_Seaweed_Bamboo_MCC_Fil ms_Food_Packaging_15172.pdf

13 S. A. Mohamed, M. El-Sakhawy, E. S. Nashy and A. M. Othman, Int. J. Biol. Macromol., 136, 774 (2019), https://doi.org/10.1016/j.ijbiomac.2019.06.130

14 A. Adel, A. El-Shafei, A. Ibrahim and M. AlShemy, Ind. Crop. Prod., 124, 155 (2018), https://doi.org/10.1016/j.indcrop.2018.07.073

15 M. El-Sakhawy, H. A. Tohamy, A. Salama and S. Kamel, Cellulose Chem. Technol., 53, 667 (2019), https://doi.org/10.35812/CelluloseChemTechnol.2019. 53.65 